\title{
ZONEAMENTO AGROCLIMÁTICO DA CULTURA DO CAFÉ PARA A BACIA DO RIO DOCE
}

\author{
EDSON LUÍS NUNES, RANIERI CARLOS FERREIRA DE AMORIM, \\ WESLEY GONÇALVES DE SOUZA, ARISTIDES RIBEIRO, \\ MÔNICA CARNEIRO ALVES SENNA e BRAULIRO GOMES LEAL
}

\author{
Universidade Federal de Viçosa (UFV), Departamento de Engenharia Agrícola, \\ Pós-Graduação em Meteorologia Agrícola. \\ Av. P.H. Rolfs, s/nº, CEP: 36570-000, Viçosa, MG. \\ E-mail: elnunes@vicosa.ufv.br,rcfamorim@gmail.com, wesley.gs@gmail.com, ribeiro@ufv.br, \\ monicasenna@gmail.com,brauliro@gmail.com.
}

Recebido Janeiro 2006 - Aceito Março 2006

\begin{abstract}
RESUMO
Objetivou-se neste trabalho, através da geoespacialização, a identificação das regiões aptas, restritas e inaptas ao cultivo do café (Coffea arabica L.) na Bacia do Rio Doce. Utilizou-se para tal, dados de temperatura e déficit hídrico de 50 estações meteorológicas instaladas na bacia e em bacias limítrofes. Os dados de déficit hídrico foram determinados utilizando o balanço hídrico segundo Thornthwaite \& Mather (1955). Foram identificadas regiões equivalentes a um terço da bacia, localizadas na parte central e no nordeste da mesma, como sendo inaptas ao cultivo do café, conforme os critérios de produtividade relacionados com as exigências térmicas e hídricas da cultura.
\end{abstract}

Palavras-chave: geoespacialização, temperatura e déficit hídrico.

\begin{abstract}
AGRICULTURE-CLIMATOLOGICAL ZONING OF COFFEE CROP FOR THE RIO DOCE BASIN.

It was aimed in this work, through the geospatialization, the identification of the apt, restricted and inapt regions for cultivation of coffee (Coffea arabica L.) in Rio Doce watershed. It was used for such, temperature and water deficit data of 50 meteorological stations installed in the watershed and in bordering watershed. The data of water deficit were determined using the water balance according to Thornthwaite \& Mather (1955). They were identified equivalent regions the one third of the watershed, located in the central part and in the northeast of the same, as being inapt to the cultivation of coffee, according to the productivity criterions related with the thermal and hydric demands of culture.
\end{abstract}

Keywords: geospatialization, temperature and water deficit.

\section{INTRODUÇÃO}

Segundo Gargantini \& Hernandez (2003) para cada R\$ 4,00 (Quatro Reais) produzidos na economia deste país, um é proveniente do complexo agroindustrial e ainda o agronegócio proporciona 37 oportunidades de emprego para cada grupo de cem empregados.

Toda essa importância do agronegócio, quando inserida em uma economia globalizada, exige que a agricultura nacional se adapte às novas circunstâncias e complexidades, sendo forçada a buscar a eficiência em um ambiente de competitividade aguçada, em que os produtores rurais, freqüentemente sujeitos às influências de uma nova ordem internacional, devem aperfeiçoar as técnicas, através de um sistema gerencial com o melhor aproveitamento possível dos recursos produtivos.

Conforme Santos (1999), o zoneamento agrícola constitui uma tarefa de fundamental importância na organização dos programas de trabalho e suporte do planejamento da agricultura. Ele se baseia no levantamento dos fatores que definem as aptidões agrícolas, encontradas em diferentes faixas da região estudada. O conhecimento das condições edafoclimáticas de determinada região é de extrema importância para a cultura do café, visto que a delimitação das regiões climaticamente homogêneas pode estabelecer os indicadores do meio físico e 
biológico para a região, além de identificar áreas com condições homogêneas para o desenvolvimento de atividades e gerenciamento dos recursos naturais nela existentes.

O zoneamento agrícola de uma região deve ser constantemente atualizado visando obter maiores informações sobre as condições climáticas das culturas selecionadas e, sobretudo, proporcionar maior retorno dos investimentos a médio e a longo prazo para os produtores. Há necessidade, portanto, da organização de banco de dados mais completos e consistentes, bem como a utilização de métodos mais modernos e sofisticados no delineamento dos limites climáticos para o atendimento à adaptabilidade de novas variedades (Sediyama et al., 2001).

Desde a sua introdução no Brasil, a cultura do café (Coffea arabica L.) tem demonstrado grande significância para a agricultura e a economia brasileira. Inicialmente, a cafeicultura se desenvolveu em regiões consideradas aptas à cultura, no que diz respeito às necessidades térmicas e hídricas, mas com a introdução da cultura em regiões consideradas marginais em termos de condições térmicas e disponibilidade hídrica, tornou-se necessária a adoção de novas tecnologias de cultivo, em especial a irrigação.

Temperaturas iguais ou superiores a $34{ }^{\circ} \mathrm{C}$ podem favorecer o abortamento floral dos cafeeiros e a formação de "estrelinhas", diminuindo, consideravelmente, a produtividade. Temperaturas iguais ou inferiores a $2{ }^{\circ} \mathrm{C}$ implicam na formação de geadas de irradiação. Por outro lado, as encostas de face Sul e Sudoeste podem estar sob influência de ventos moderados a fortes, com temperaturas baixas, ocasionando sintomas típicos de "crestamento" foliar no período de inverno (Camargo et al., 1974).

De acordo com Matiello (1991), no período de vegetação e frutificação, que vai de outubro a maio, o cafeeiro é exigente em água e, na fase de colheita e repouso, de junho a setembro, a exigência é menor podendo haver pequena deficiência hídrica, sem grandes prejuízos para a cultura.

A técnica de irrigação, quando utilizada de forma racional, pode contribuir para a melhoria do desempenho do agronegócio de uma região, a qual pode ser considerada como um elemento importante na diversificação agrícola e como facilitadora da capitalização na agropecuária, além de possibilitar colheitas fora de época e melhoria da qualidade da produção. Entretanto, de acordo com Fernandes et al. (2000), ainda são necessários estudos que visem proporcionar ao irrigante a garantia de poder atender às necessidades hídricas das plantas no momento adequado e em quantidades suficientes. A irrigação evita o déficit hídrico, que pode afetar, tanto em quantidade como em qualidade, a produção da cultura (Gomide, 1998).

A evapotranspiração é considerada como a perda total de água para a atmosfera por evaporação da água do solo e transpiração das plantas, sendo importante para o balanço hídrico de uma bacia como um todo e, principalmente, para o balanço hídrico agrícola, que poderá envolver o cálculo da necessidade de irrigação (Tucci \& Beltrame, 2001). Os fatores climáticos interferem de forma decisiva na evapotranspiração de uma cultura; as condições do solo, doenças, pragas, a própria cultura e suas características de crescimento, além de práticas agrícolas, também influenciam a transferência de água para a atmosfera (Klar, 1984).

A comparação entre precipitação pluviométrica $(\mathrm{P})$ e evapotranspiração potencial (ETp) resulta no balanço hídrico climatológico, indicando excessos e deficiências de umidade ao longo do ano ou da estação de crescimento das culturas.

A evapotranspiração real (ETr) é aquela que ocorre numa superfície vegetada, independente de sua área, de seu porte e das condições de umidade do solo (Pereira et al., 1997). A ETr é igual ou menor que a ETp. Sendo um processo complexo e extremamente dinâmico, que envolve organismos vivos como o solo e a planta, a evapotranspiração real é muito difícil de ser estabelecida em termos absolutos. Entretanto, a conjugação de inúmeras informações associadas ao conceito de ETp, permite obter estimativas confiáveis (Tucci \& Beltrame, 2001).

De acordo com Pereira et al. (1997), o balanço hídrico se constitui no sistema contábil de monitoramento de água no solo, onde são fornecidos dados de precipitação e de demanda atmosférica para serem estimados valores de evapotranspiração real, da deficiência, do excedente e do armazenamento de água no solo. Trata-se de um método bastante simples de manejo da irrigação. Existem diversos métodos para o cálculo do balanço hídrico, mas o mais difundido é o proposto por Thornthwaite \& Mather (1955).

Referindo-se às exigências térmicas e hídricas, Matiello (1991), estabeleceu parâmetros técnicos para o zoneamento climático da cultura do café, conforme Tabela 1.

Tabela 1 - Parâmetros técnicos para o zoneamento climático da cultura do café.

\begin{tabular}{ccc}
\hline Aptidão & $\begin{array}{c}\text { Temperatura } \\
{ }^{\mathbf{0}} \mathbf{C}\end{array}$ & $\begin{array}{c}\text { Déficit hídrico } \\
\mathbf{m m}\end{array}$ \\
\hline Regiões aptas & $19-22$ & $<150$ \\
Regiões restritas & $18-19$ e $22-23$ & $150-200$ \\
Regiões inaptas & $<18$ e $>23$ & $>200$ \\
\hline
\end{tabular}

Essas três classes de aptidão possuem as seguintes características: Aptas: quando a região apresenta condições térmicas e hídricas favoráveis à exploração da cafeicultura; Restrita: quando a região apresenta restrição térmica ou hídrica. Nesta classe, a cultura poderá, eventualmente, encontrar aptidão, desde que os fatores de restrição sejam controlados; Inapta: quando as características do clima não são adequadas à exploração 
comercial da cultura, em razão das limitações graves dos fatores térmicos e hídricos.

Compreender a distribuição espacial de dados oriundos de fenômenos ocorridos no espaço constitui hoje um grande desafio para a elucidação de questões centrais em diversas áreas do conhecimento, seja em saúde, em ambiente, em geologia, em agronomia, entre tantas outras. Tais estudos vêm se tornando cada vez mais comuns, devido à disponibilidade de sistemas de informações geográficas (SIG) de baixo custo e com interfaces de fácil utilização. Estes sistemas permitem a visualização espacial de variáveis numa região através de mapas. Para tanto, basta dispor de um banco de dados e de uma base geográfica e o SIG é capaz de apresentar um mapa colorido permitindo a visualização do padrão espacial do fenômeno.

A análise espacial é composta por um conjunto de procedimentos encadeados cuja finalidade é a escolha de um modelo inferencial que considere explicitamente o relacionamento espacial presente no fenômeno. Os procedimentos iniciais da análise incluem o conjunto de métodos genéricos de análise exploratória e a visualização dos dados, em geral através de mapas. Essas técnicas permitem descrever a distribuição das variáveis em estudo e identificar observações atípicas (outliers), não somente em relação ao tipo de padrão na distribuição espacial. Através desses procedimentos é possível estabelecer hipóteses sobre as observações, de forma a selecionar o modelo inferencial melhor suportado pelos dados (Druck et al., 2004).

A ênfase da análise espacial é mensurar propriedades e relacionamentos, levando em conta a localização espacial do fenômeno em estudo de forma explícita. Ou seja, a idéia central é incorporar o espaço à análise que se deseja fazer.

Quando se tem uma amostra de pontos ou valores espaçados irregularmente numa região ou numa área, e deseja-se criar uma rede, malha ou um gride regular de valores, ou seja, uma superfície raster, utiliza-se o método da interpolação.

A interpolação prediz valores para uma célula em um raster a partir de um número limitado de pontos numa amostra. Ela pode ser usada para predizer valores desconhecidos para quaisquer pontos geográficos: elevação, chuva, concentrações químicas, e assim por diante.

Um problema quando se cria um raster por intermédio da interpolação, é que os valores originais da informação são degradados em algumas extensões - até mesmo quando um ponto cai dentro de uma célula, não é garantido que a célula terá exatamente o mesmo valor. A interpolação está baseada na suposição de que objetos distribuídos espacialmente são espacialmente correlacionados; em outras palavras, objetos que estão próximos tendem a ter características similares.

Existem vários métodos para criar uma superfície raster de dados pontuais. Pode-se usar o Inverso da Distância (IDW), Spline e Krigeagem. Cada método de interpolação faz suposi- ções sobre como determinar os valores estimados. Dependendo do fenômeno que será modelado e da distribuição amostral dos pontos, diferentes interpoladores produzem bons modelos da superfície real. Independente do interpolador, a fidedignidade dos resultados irá depender da quantidade de pontos e da sua distribuição (Booth, 2001).

Este trabalho teve como objetivo, através da geoespacialização, identificar as regiões aptas, restritas e inaptas ao cultivo do café (Coffea arabica L.) na Bacia do Rio Doce, situada na região leste do estado de Minas Gerais e norte do estado do Espírito Santo.

\section{DADOS E METODOLOGIA}

Foram utilizados dados climáticos de 50 estações meteorológicas localizadas na Bacia do Rio Doce e nas bacias limítrofes (Figura 1). Os dados de temperatura do ar foram obtidos das normais climatológicas do Instituto Nacional de Meteorologia (INMET/MAPA, 1992) para o período de 1961 a 1990, enquanto que os dados de precipitação totais mensais foram obtidos através da Agência Nacional de Energia Elétrica (ANEEL, 1999).

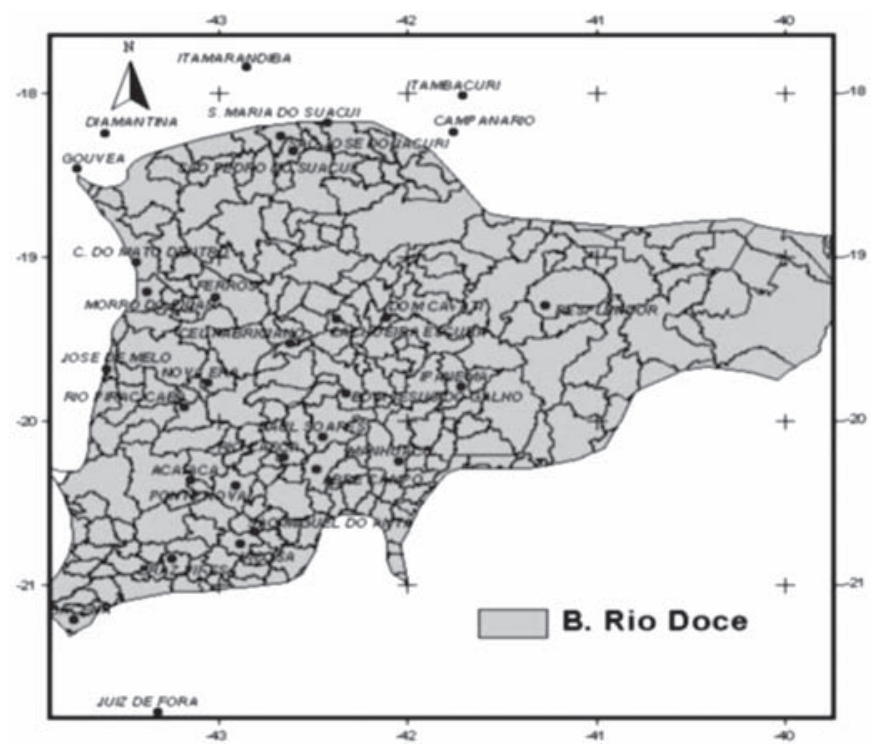

Figura 1 - Distribuição espacial das estações meteorológicas na bacia do Rio Doce e estações limítrofes.

No processo de espacialização foram utilizados dados climáticos de temperatura (Ta), ETr e ETp. Os dados de ETr e ETp foram calculados pela Empresa Brasileira de Agropecuária (EMBRAPA) através do método de Thornthwaite \& Matter (1955) e disponibilizados pela MÍDIA CAFÉ (2002).

O defícit hídrico foi calculado pela diferença entre a evapotranspiração potencial e a evapotranspiração real da cultura. 
Utilizou-se o software ArcGIS Desktop 8.3 para importar os dados, e para processar a interpolação, utilizou-se o módulo Spatial Analysis do mesmo software, gerando assim os mapas com a geoespacialização da temperatura e do déficit hídrico para a Bacia do Rio Doce.

Utilizou-se o método de interpolação do inverso da distância (IDW), que é um interpolador local, determinístico e exato.

Para o cálculo da interpolação dos dados utilizou-se o modelo matemático:

$$
\hat{Z}=\frac{\sum_{i=1}^{n} \frac{1}{d_{i}^{p}} \cdot Z_{i}}{\sum_{i=1}^{n} \frac{1}{d_{i}^{p}}}
$$

onde: $\hat{Z}$ é o valor interpolado; $\mathrm{d}$ é a distância de um dado ponto conhecido i; $\mathrm{z}$ é o valor de $\mathrm{z}$ do ponto conhecido i; $\mathrm{p}$ é o expoente de ponderação da distância; $\mathrm{n}$ é o número de pontos a serem incluídos na procura; i é o número do ponto conhecido considerado.

Após proceder a interpolação para os temas temperatura e déficit hídrico, os mesmos foram reclassificados segundo os parâmetros técnicos estabelecidos por Matiello (1991), referentes à cultura do café, gerando assim os mapas temáticos para temperatura e déficit hídrico, os quais constam das áreas Aptas, Restritas e Inaptas para a produtividade do café. A partir desses resultados, reproduziu-se em um único mapa, correspondente ao zoneamento climático da aptidão ao cultivo do café (Coffea arabica L.) para a Bacia do Rio Doce, através de uma operação de álgebra de mapas disponível no ArcGIS no módulo Spatial Analysis. O mapa resultante desta operação foi reclassificado, obtendo com isso, um mapa final contendo as áreas Aptas, Restritas e Inaptas ao cultivo do café para a bacia, obedecendo aos critérios de produtividade relacionados com as condições térmicas e hídricas da cultura (Tabela 1).

\section{RESULTADOS E DISCUSSÕES}

Na Figura 2 é apresentado o mapa temático de temperatura média anual para a Bacia do Rio Doce. Nesta figura, observa-se que as temperaturas mais baixas ocorrem nas regiões Sul e Oeste da bacia, ou seja, nas regiões mais altas da bacia. As temperaturas mais altas ocorrem nas regiões Norte e Nordeste da bacia, locais de menores altitudes e latitudes da bacia.

A geoespacialização da deficiência hídrica anual na Bacia do Rio Doce, pelo método do balanço hídrico descrito por Thornthwaite \& Matter (1955), revelou valores superiores a 20 $\mathrm{mm}$. Os valores mais elevados ocorreram na região mais baixa da bacia (Norte e Nordeste), locais de maiores temperaturas anuais. A amplitude anual do déficit hídrico foi de $266 \mathrm{~mm}$, conforme Figura 3.

Com relação à aptidão térmica, na Figura 4, observamse condições favoráveis ao plantio de café em uma faixa de aproximadamente um terço da bacia, que se estende da região Sul, passando por toda região Oeste, até a região Norte da bacia. As regiões Leste e central da bacia apresentam condições desfavoráveis ao cultivo de café, enquanto que pequenas áreas situadas nas regiões Noroeste e Sudoeste da bacia e uma grande área central que se estende de Norte a Sul apresentam restrição térmica ao cultivo do café.

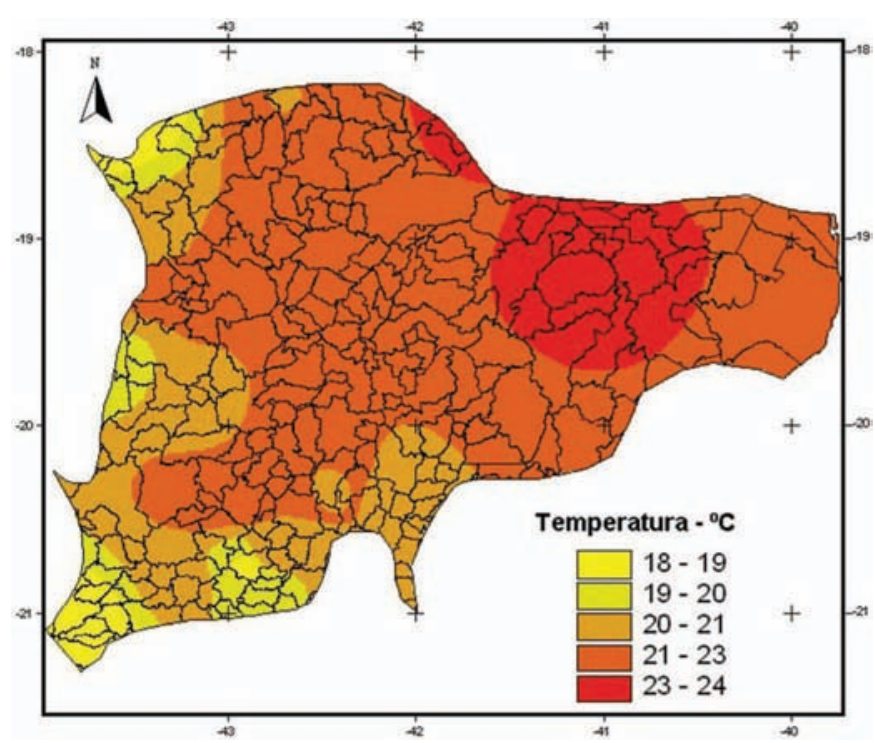

Figura 2 - Interpolação da temperatura anual para a bacia do Rio Doce.

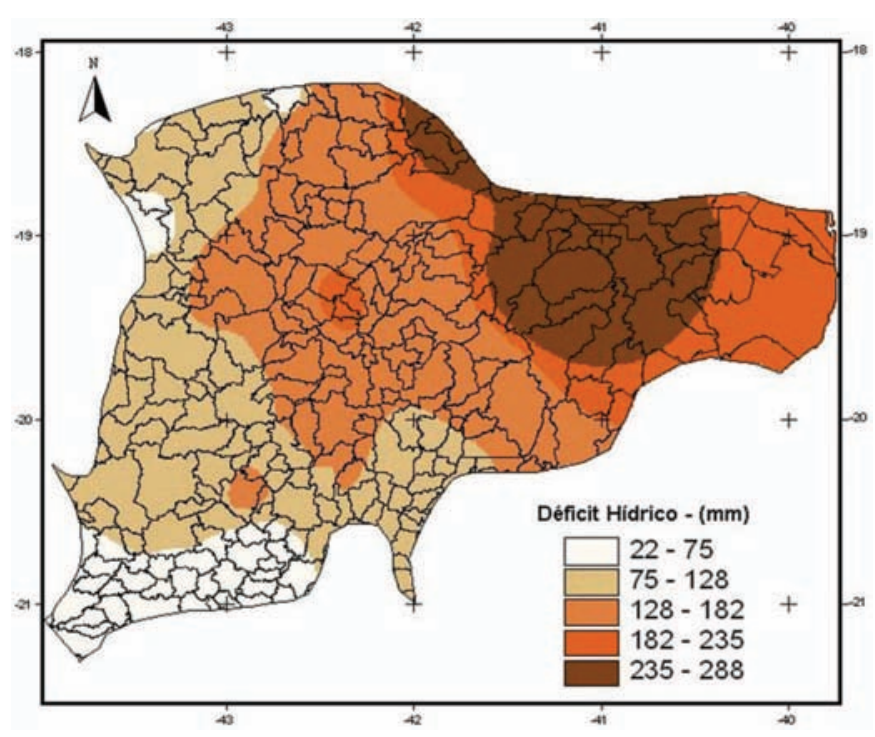

Figura 3 - Interpolação do déficit hídrico anual para a bacia do Rio Doce. 


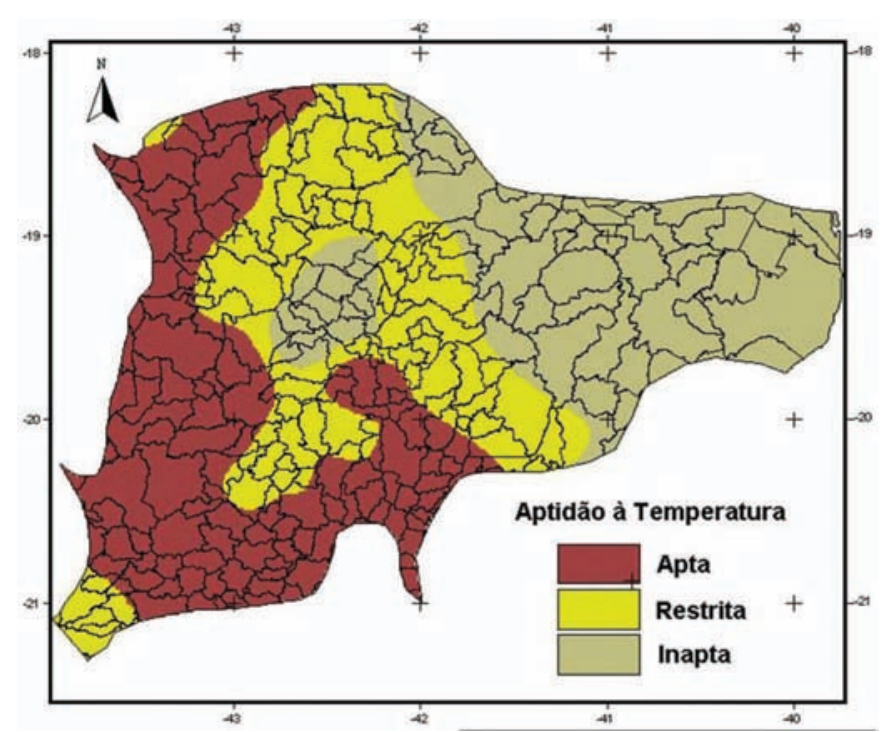

Figura 4 - Mapa da aptidão térmica para o cultivo do café (Coffea arabica L.) na bacia do Rio Doce.

Os resultados referentes às zonas de aptidão ao déficit hídrico para a cultura do café na bacia do Rio Doce são apresentados na Figura 5. No mapa de aptidão ao déficit hídrico, é possível observar que, praticamente, mais da metade da bacia possui condições favoráveis ao cultivo café, abrangendo a região mais alta da bacia. À medida que se aproxima da região leste da bacia (região baixa), observam-se restrições ao cultivo do café, em razão dos menores índices de precipitação pluvial e maior demanda evapotranspirativa, fatores que, de modo geral, condicionam baixo armazenamento de água no solo restringindo, portanto, o cultivo do café.

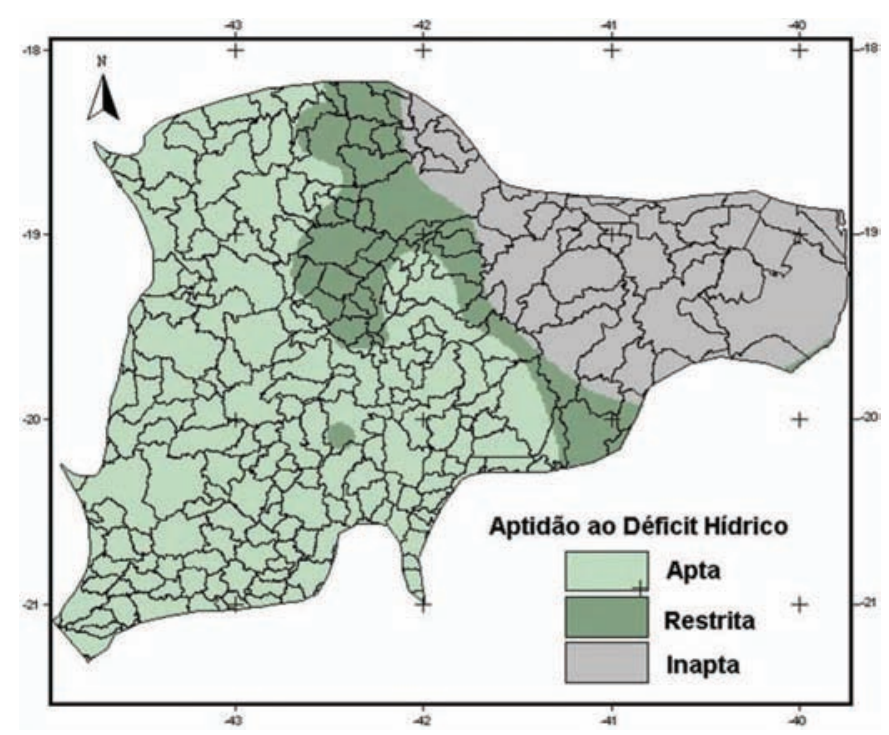

Figura 5 - Mapa da aptidão hídrica para o cultivo do café (Coffea arabica L.) na bacia do Rio Doce.
A Figura 6 apresenta o zoneamento climático da aptidão ao cultivo do café para a Bacia do Rio Doce, cujos resultados mostram que, sob o ponto de vista climático, cerca de um terço da parte alta da bacia apresenta condições adequadas ao cultivo do café. Enquanto que regiões, com área igual a aproximadamente um terço da bacia, localizada na região central, Noroeste e Sudoeste, podem ser cultivados, embora apresentando alguma restrição devido à temperatura do ar ou deficiência hídrica, resultados idênticos aos encontrados por Sediyama et al. (2001). Nessas regiões o cultivo pode ser realizado adotandose técnicas de manejo, como por exemplo a suplementação de água por irrigação, de modo a ajustar o fator restritivo e tornar essas áreas potencialmente produtivas. Regiões equivalentes a um terço da área da bacia, localizadas na parte central e baixa da mesma são consideradas inaptas ao cultivo de café. Os resultados de inaptidão ao cultivo do café (Coffea arabica L.) para a região leste da bacia do Rio Doce, situada no norte do estado do Espírito Santo, foram similares aos encontrados por Sediyama et al. (2000) no zoneamento climático da cultura do café (Coffea arabica L.) para o Espírito Santo.

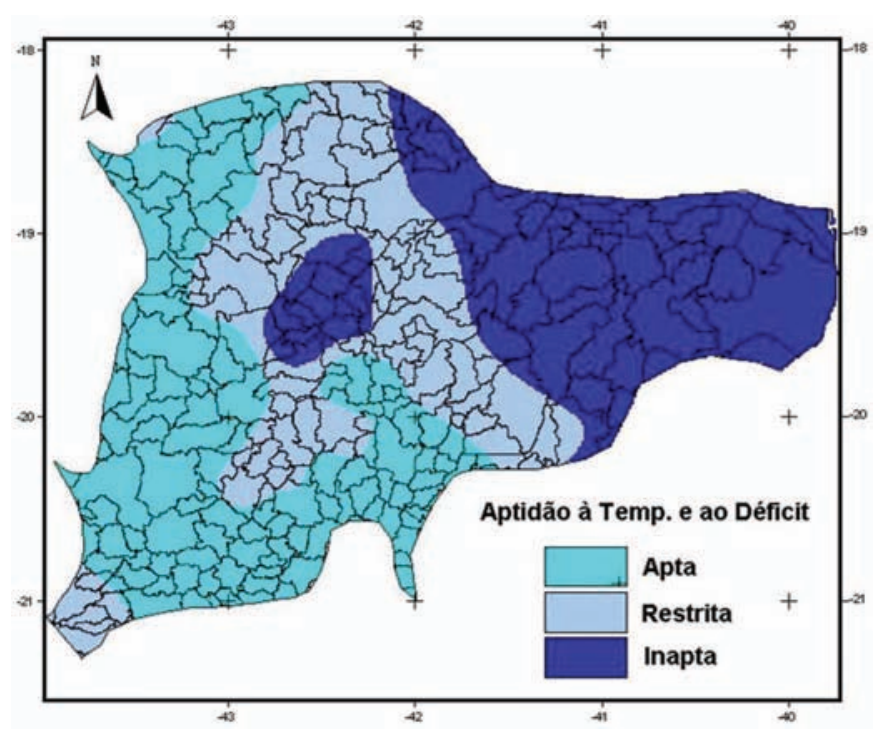

Figura 6 - Zoneamento climático da aptidão ao cultivo do café ( Coffea arabica L.) para a bacia do Rio Doce

\section{CONCLUSÕES}

Aproximadamente um terço da área da bacia (regiões central e Leste) é inapta ao cultivo do café, devido à ocorrência de um déficit hídrico maior que $150 \mathrm{~mm}$ e altas temperaturas $\left(>23^{\circ} \mathrm{C}\right)$.

Aproximadamente dois terços da área da bacia, localizada na parte mais alta, é apta ao cultivo do café ou possui alguma restrição térmica ou hídrica que pode eventualmente ser corrigida. 


\section{REFERÊNCIAS BIBLIOGRÁFICAS}

ANEEL. Agência Nacional de Energia Elétrica, Governo Federal (Brasil), 1999. http://www.aneel.gov.br/.

BOOTH, B. Using ArcGIS 3D Analysis. New York: ESRI Press, 2001.

CAMARGO, A. P. de; PINTO, H. S.; PEDRO JR., M. J. Aptidão climática de culturas agrícolas. In: SÃO PAULO. Secretaria da Agricultura. Zoneamento agrícola do estado de São Paulo. CATI, v. 1, p. 109-149, 1974.

DRUCK, S. et al. Análise Espacial de Dados Geográficos. Brasília, EMBRAPA: 2004.

FERNANDES, A.L.T. et al. Deficiência hídrica e uso de granulados em lavoura cafeeira irrigada por gotejamento. Revista Brasileira de Engenharia Agrícola e Ambiental, v. 4, n. 3, p. 376-381, 2000.

GARGAnTINI, P.E.; HERnANDEZ, F.B.T. A Cidade: Desenvolvendo com a Agricultura Irrigada e o Agronegócio. Ribeirão Preto: 2003, 3p.

GOMIDE, R.L. Monitoramento para Manejo da Irrigação: Instrumentação, Automação e Métodos. In: FARIA, M.A. et al. Manejo da Irrigação. Lavras: UFLA/SBEA, 1998, p. 133-238.

INMET/MAPA. Instituto Nacional de Meteorologia. Normais climatológicas (1961-90). Brasília: 1992, 84p.
KLAR, A. E. A água no sistema solo-planta-atmosfera. São Paulo: Nobel, 1984. 408 p.

MATIELLO, J. B. O café: do cultivo ao consumo. Globo Rural, Coleção do agricultor - Grãos, 320 p., 1991.

MÍDIA CAFÉ. Zoneamento do Café. Consórcio Brasileiro de Pesquisa e Desenvolvimento do Café, 2002. CD-ROM.

PEREIRA, A. R.; VILLA NOVA, N. A.; SEDIYAMA, G. C. Evapo(transpi)ração. Piracicaba: ESALQ/USP, 1997. 183p.

SANTOS, A. R. dos. Zoneamento agroclimático para a cultura do café conilon (Coffea canephora L.) e arábica (Coffea arabica L.), na bacia do Itapemirim, ES. 1999. 59 f. Dissertação (Mestrado em Meteorologia Agrícola) - Universidade Federal Viçosa, 1999.

SEDIYAMA, G. C. et al. Zoneamento climático do cafeeiro para o estado do Espírito Santo. Programa Nacional de Pesquisa \& Desenvolvimento/Café, 2000.

SEDIYAMA, G. C. et al. Zoneamento agroclimático do cafeeiro (Coffea arábica L.) para o estado de Minas Gerais. Revista Brasileira de Agrometeorologia, v. 9, n. 3, p.501-509, 2001.

THORNTHWAITE C. W.; MATHER, J. R. The water balance. Publications in Climatology, New Jersey, Drexel Institute of Technology, 104 p., 1955.

TUCCI, A. E. M.; BELTRAME, L. F. S. Evaporação e evapotranspiração. In: TUCCI, A. E. M. Hidrologia: ciência e aplicação. Porto Alegre: UFRGS, 2001. 943 p. 